\title{
IMPLEMENTAÇÃO DE HORTA MEDICINAL: UMA ALTERNATIVA PARA AULAS PRÁTICAS NA ESCOLA DO CAMPO
}

\author{
Gisele Arruda ${ }^{1}$ \\ Letícia Yabushita Rigoti ${ }^{2}$ \\ Caroline Valente ${ }^{3}$
}

\begin{abstract}
Resumo: A utilização de metodologias diversificadas nas aulas de biologia e ciências podem estar ligadas ao enriquecimento intelectual dos alunos, devido à sua participação nas atividades práticas. Nesse contexto, o trabalho pretende destacar a contribuição do professor de biologia frente à implementação de hortas medicinais como alternativa para as aulas práticas desenvolvidas na escola do campo. Para tal fim, foi implementado uma horta de plantas medicinais em uma escola do município de Salto do Lontra-PR, como forma de colaborar no desenvolvimento educacional dos alunos da escola do campo. A pesquisa será de campo do tipo levantamento de dados, com metodologia exploratório ou descritiva e abordagem qualitativa. A implementação da horta medicinal mostrou que $100 \%$ dos alunos e professores afirmaram que aulas práticas, como o da horta medicinal, trazem um melhor aprendizado, destacando assim um aprimoramento da relação teoria e prática, pois os alunos puderam aprender e executar atividades práticas relacionadas com o conteúdo teórico.
\end{abstract}

Palavras Chaves: Educação do campo. Plantas medicinais. Prática pedagógica.

\section{IMPLEMENTATION OF MEDICINAL GARDEN: A PRACTICAL ALTERNATIVE TO SCHOOL IN THE FIELD}

\begin{abstract}
The use of different methodologies in biology classes and science can be linked to the intellectual enrichment of students, due to their participation in practical activities. In this context, the paper aims to highlight the contribution of biology teachers facing the implementation of medicinal gardens as an alternative for the practical lessons developed in the field school. To this end, a garden of medicinal plants at a school in the municipality of Salto do Lontra - PR as a way to collaborate in the educational development of the students of the course was implemented. The search will field data collection type, with exploratory and descriptive qualitative methodology and approach. The implementation of the medicinal garden showed that $100 \%$ of students and teachers stated that the practical lessons, such as the medicinal garden, bring better learning, thus highlighting an improvement in theory and practice relationship because the students could learn and perform practical activities related to the theoretical content.
\end{abstract}

Keywords: Field education. Medicinal plants. Pedagogical practice.

\section{APLICACIÓN DEL MEDICAMENTO JARDÍN: UMA ALTERNATIVA PRÁCTICA A ESCUELA EN EL CAMPO}

RESUMEN: El uso de diferentes metodologías en las clases de biología y la ciencia puede estar relacionado con el enriquecimiento intelectual de los estudiantes, debido a su participación en las actividades prácticas. En este contexto, el artículo se destaca la contribución de los profesores de biología que enfrenta la implementación de huertos medicinales como alternativa para las clases prácticas se desarrollan en la escuela de campo. Con este fin, un jardín de plantas medicinales en una escuela en el municipio de Salto do Lontra -PR como se implementó una manera de colaborar en el desarrollo educativo de los alumnos del curso. La búsqueda será el campo de tipo de colección de datos, con metodología cualitativa exploratoria y descriptiva y el enfoque. La implementación del jardín medicinal mostró que el $100 \%$ de los estudiantes y los profesores afirmó que las lecciones prácticas, como el jardín de plantas medicinales, llevar un mejor aprendizaje, que pone de relieve una mejora en la teoría y la práctica de la relación

\footnotetext{
${ }^{1}$ Docente da Universidades Estadual do Oeste do Paraná, campus Francisco Beltrão. Centro de Ciências da Saúde. Doutora em Biologia Comparada. giselearrudabioq@gmail.com

2 Discente de Medicina, Universidades Estadual do Oeste do Paraná, campus Francisco Beltrão. leticia.y.rigoti@gmail.com

${ }^{3}$ Docente da Faculdade Regional de Blumenau, campus Blumenau. Departamento de Ciências Naturais/Centro de Ciências Exatas e Naturais. Doutora em Ciências Bioquímica. carolvalente11@gmail.com
} 


\section{FAZ CIÊNCIA, VOL. 22, N. 35, JA/JUN DE 2020 - P. 06-08}

debido a que los estudiantes pudieran aprender y realizar actividades prácticas relacionadas con los contenidos teóricos.

Palabras Clave: La educación del campo. Las plantas medicinales. La práctica pedagógica.

\section{Introdução}

As metodologias utilizadas para o ensino da Biologia são resultadas do grande desenvolvimento científico que permeou as décadas de 50 e 60 e revolucionou a ciência (KRASILCHIK, 2004). Esta revolução trouxe ao ensino da Biologia, além das funções que já desempenhava no currículo escolar, outra, que é a de aproximar a ciência e seus saberes ao cotidiano do aluno, fazendo-o perceber a importância do conhecimento científico como instrumento de transformação e entendimento do mundo que o cerca. Assim, Moreira e Diniz (2003), destacam que a experimentação no ensino da Biologia é de suma importância e praticamente inquestionável, pois permite contato com os fenômenos naturais e materiais biológicos, manipulações, discussões, tentativas e ação.

Segundo Lima et al., (1999), a experimentação inter-relaciona o aprendiz e os objetos de seu conhecimento, à teoria e à prática, ou seja, une a interpretação do sujeito aos fenômenos e processos observados, pautados não apenas pelo conhecimento científico já estabelecido, mas pelos saberes e hipóteses levantados pelos alunos diante de situações desafiadoras.

Assim, o trabalho tem o objetivo de destacar a importância e a contribuição do professor de biologia frente à implementação de hortas medicinais como alternativa para as aulas práticas desenvolvidas na escola do campo. Essa prática pode trazer uma relação dos conteúdos teóricos (como solo, água, meio ambiente, plantas, cultivo de plantas, reino plantae, temperatura, entre outros) com a prática elaborada pelo professor junto com os alunos.

\section{Hortas Medicinais}

O cultivo de plantas é uma prática comum em cidades do interior, nas quais são desenvolvidas hortas em escolas, bairros e no próprio quintal, garantindo uma produção para atender a demanda de uma pequena parcela da população familiar ou local, sem fins lucrativos.

Dentre essas hortas, destacam-se as de cultivo de plantas medicinais, que vêm a cada dia conquistando seu espaço no tratamento de inúmeras enfermidades, garantindo a cura de doenças animais e vegetais, garantindo o aumento da renda de produtores rurais. Segundo Rodrigues e Carvalho (2001), as plantas medicinais atuam no combate às doenças, destruindo ou inibindo o desenvolvimento de agentes patogênicos, na purificação do organismo, expelindo toxinas neutralizando a ação de bactérias, parasitas, entre outros. 


\section{FAZ CIÊNCIA, VOL. 22, N. 35, JA/JUN DE 2020 - P. 06-08}

As plantas medicinais apresentam valor para a medicina tradicional como tratamento de doenças pela população de baixa renda, tendo em vista as deficiências do sistema de saúde pública nacional. Percebe-se a expansão dos estudos científicos para a comprovação de ditos populares a respeito do emprego de plantas medicinais na cura de doenças, e no isolamento de princípios ativos com o objetivo de desenvolver novos fármacos a serem comercializados. Para Arnous, Santos e Beinner (2005), são necessárias pesquisas que apontem os benefícios de hortas medicinais para promoção e melhoria da saúde pública e possam contribuir com modelos que integrem o papel social, o ambiente físico e as perspectivas integradas para fortalecimento da capacidade comunitária, com efetiva promoção da saúde no nível local.

Morgado (2006) destaca que a horta inserida no ambiente escolar pode ser um laboratório vivo que possibilita o desenvolvimento de diversas atividades pedagógicas em educação ambiental e capaz de unir teoria e prática de forma contextualizada, auxiliando no processo de ensinoaprendizagem, estreitando relações através da promoção do trabalho coletivo e cooperado entre os agentes sociais envolvidos (MORGADO, 2006).

Nesse aspecto, Armstrong (2000) discute que programas que envolvem a comunidade no cultivo de jardins ou hortas medicinais revelam membros da comunidade que são desejosos de se engajarem neste tipo de atividade para promoção da saúde.

Desta maneira, o trabalho tem como objetivo envolver toda a comunidade escolar em um trabalho participativo, através da implementação de uma horta medicinal na escola, pela qual todos se sintam responsáveis, sendo abordados temas sobre cultivo, coleta, armazenamento e uso correto das mesmas, uma vez que algumas plantas também podem ser tóxicas. No trabalho foram utilizadas as plantas conhecidas popularmente como babosa, erva cidreira, novalgina ou pontalivio, poejo e tansagem.

\section{Implementação da Horta Medicinal}

Para iniciar uma horta Medicinal é necessário selecionar as espécies e identificar corretamente as plantas. Uma horta medicinal, por certo, deverá produzir satisfatoriamente, ervas que podem ser usadas na culinária, temperos e aquelas de uso de rotina para o tratamento de doenças mais comuns do organismo. A escolha de qual planta cultivar vai de acordo com os interesses.

O local a ser escolhido para implementação de uma horta medicinal deverá ter água disponível em abundância e de boa qualidade, e exposto ao sol, principalmente pela manhã. O solo 
deve ser leve e fértil para que as raízes tenham facilidade de penetrar e desenvolver. Quanto aos aspectos físicos do solo, pode ser melhorado, no seu preparo, incorporando no mesmo, esterco e/ou composto orgânico, onde fornecerá nutrientes que ajudarão a reter a umidade (UNIVERSIDADE DE SÃO PAULO, 2012). Na correção do solo, não deve ser utilizados fertilizantes químicos, pois esses compostos podem ser absorvidos pelas plantas e causar danos à saúde das pessoas (ORGANIZAÇÃO CANTO VERDE, 2012).

Os materiais básicos para um manejo adequado de uma horta de plantas medicinais, segundo Untaler, Fernandes e Oliveira (2011) são: ancinho, utilizado para nivelar o terreno e retirada do mato capinado; colher de Jardineiro, utilizado em operações de transplante de plantas; enxada, usada para misturar adubos, terra e nas capinações; garfo, coleta de mato e folhagem; regadores de diferentes tamanhos, permitindo manuseio das crianças e sacho para aforamento da terra a capina entre linhas de plantas.

Alguns cuidados são necessários ao manejo da horta, tais como irrigação diária, observando o melhor horário para sua efetivação; retirar plantas invasoras; afofar a terra próxima às mudas; completar nível de terra em plantas descobertas; observar a fitossanidade da horta (presença de insetos e pragas, fungos, bactérias e vírus) (UNTALER; FERNANDES; OLIVEIRA, 2011). Para a Organização Canto Verde (2012) a adubação é importantíssima, pois produzirá plantas resistentes a pragas e doenças, sendo que a utilização de agrotóxicos deve ser evitada.

Com relação à colheita das plantas medicinais devem-se seguir as seguintes etapas, segundo a Organização Canto Verde (2012), coleta, secagem e armazenamento. A coleta deve ser realizada pela manhã, logo que secar o orvalho das plantas. É sempre melhor colher as plantas medicinais em dias amenos, sem chuva, no período de estio, em horário de sol fraco e suave. A secagem pode ser realizada espalhando-se a planta ou suas partes sobre um pano ou plástico. Secar as plantas à sombra, quando essas se tornarem quebradiças, estarão prontas para uso, devendo ser guardadas em vidros fechados, longe da luz, pó e umidade. O armazenamento deve ser feito rapidamente, evitando assim a perda dos princípios ativos das plantas, preferencialmente em ambiente arejado e seco, sem acesso de poeira ou animais.

\section{Metodologia}

A pesquisa será de campo do tipo levantamento de dados, com metodologia exploratório ou descritiva e abordagem qualitativa. 


\section{FAZ CIÊNCIA, VOL. 22, N. 35, JA/JUN DE 2020 - P. 06-08}

Entre os alunos e os professores de da escola, foram escolhidos de forma não aleatória, mas intencional, formando uma amostra de 23 pessoas, sendo 5 professores e 18 alunos, da Escola Estadual de Campo Professor José Luiz Pedroso. Para a participação dos alunos, foram solicitadas autorização (Termo de Consentimento Livre e Esclarecido) para escola e pais.

No dia da implementação, foi proferida uma palestra sobre as plantas que foram trazidas para a horta, falando da importância de cada uma, para que são indicadas, como são preparadas. Posteriormente a horta foi implementada pelos alunos, com auxilio da professora. A horta foi preparada utilizando garrafas pet, como uma forma de reutilizar esse material. Durante a implementação foram realizadas correlações entre os conteúdos de ciências como água, meio ambiente, reino plantae, entre outros. Após o plantio, os alunos foram conduzidos até a sala de informática da escola para elaboração de um manual sobre as plantas medicinais que foram plantadas na horta. Esse manual foi deixado na biblioteca da escola para livre consulta.

Por conseguinte, foi aplicado um questionário composto por sete perguntas, para os alunos e professores responderem, para investigar o papel e a importância do professor de biologia na implementação de hortas medicinais na escola do campo.

\section{Resultados e Discussões}

A aplicação de aulas práticas é uma importante ferramenta que pode ser utilizada pelo professor em sala de aula. Desta forma, o trabalho buscou a implementação de uma horta de plantas medicinais na Escola Estadual do Campo Professor José Luiz Pedroso, comunidade de São Sebastião - Salto do Lontra - PR, como forma de aprendizado prático nas aulas de Ciências e Biologia.

Inicialmente foi realizada uma visita na Escola para ver o espaço disponível para a implementação da horta, nesse momento foi conversado com os alunos, equipe pedagógica e professores sobre a implementação do projeto, suas etapas e aplicação. Foi solicitado que os alunos e professores trouxessem mudas de plantas medicinais, adubo orgânico, garrafas pet, para num segundo encontro efetivar a implementação da horta medicinal.

No segundo encontro, onde foi realizada a implementação, o trabalho foi iniciado com uma palestra para os alunos e professores da escola, explicando-lhes cada uma das plantas medicinais que foram trazidas, explanado como são preparados os chás, para que são indicados, nome popular, curiosidades e dúvidas. Nesse momento foi feito uma discussão com os alunos, sobre quais dessas 
plantas os alunos já conheciam, já tinham utilizado, como haviam preparado o chá e para que esse chá havia sido utilizado na ocasião.

Posteriormente, os alunos foram encaminhados até o espaço para realização da implementação da horta. Nesse período foram explicadas as técnicas para montagem da horta, segundo estudo detalhado na literatura (UNTALER, FERNANDES, OLIVEIRA 2011; ORGANIZAÇÃO CANTO VERDE, 2012; UNIVERSIDADE DE SÃO PAULO, 2012). Primeiramente, os alunos, colocaram o adubo orgânico na terra, fazendo uma mistura de terra com o adubo, com auxílio de uma inchada, como mostra a FIGURA 01.

Enquanto um aluno misturava a terra com o adubo, foi mostrado aos alunos como colocar as garrafas pet ao redor da horta para conter a terra, como pode ser observado na FIGURA 01.

FIGURA 01: Fotografia dos alunos montando a barreira da horta com garrafas pet.

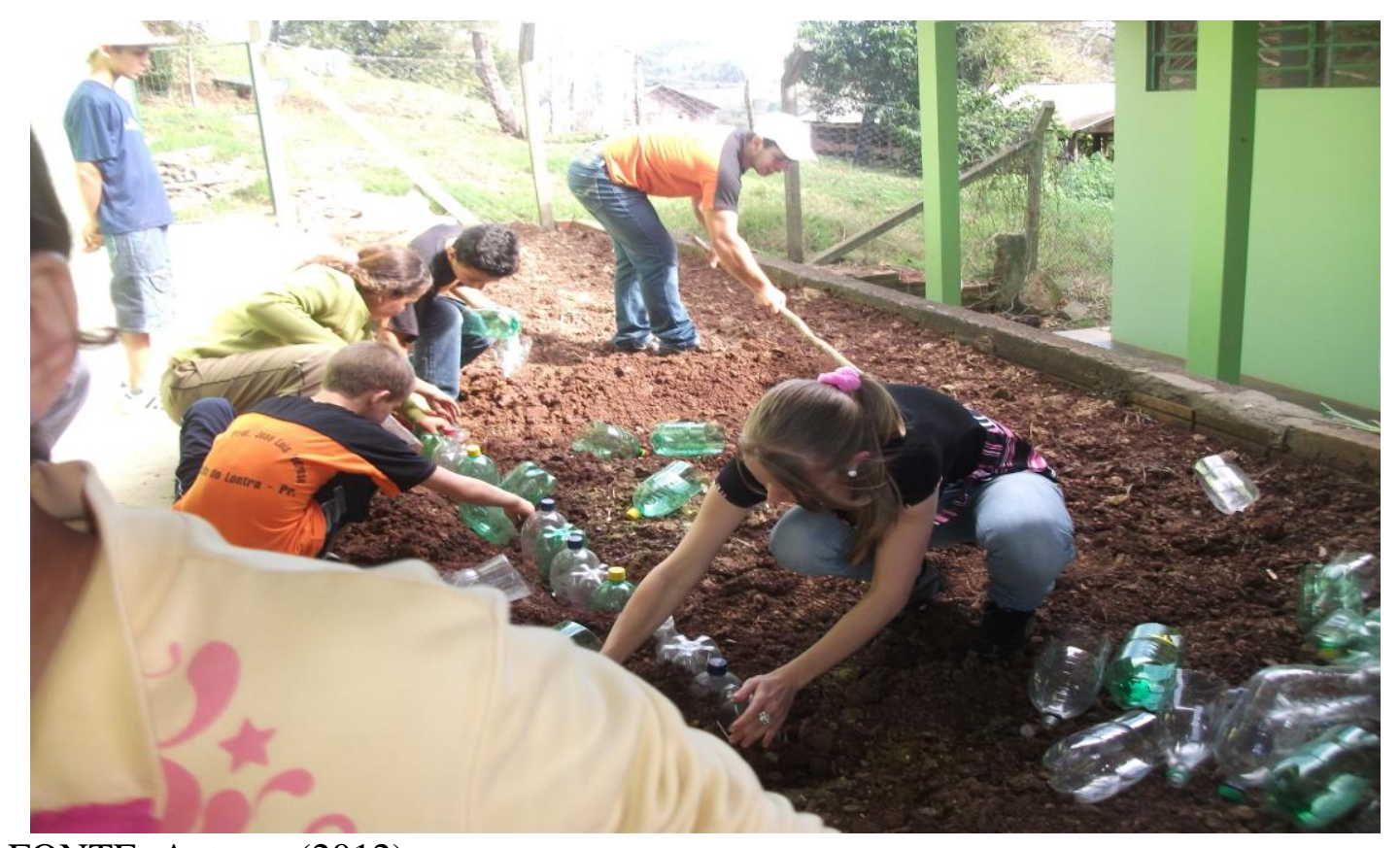

FONTE: Autoras (2012).

Após essa etapa, a terra foi regada antes do plantio das mudas. O plantio seguiu normas estabelecidas por Untaler, Fernandes, Oliveira 2011, Organização Canto Verde, 2012 e Universidade de São Paulo, 2012, com adaptações para o espaço em questão. Foram feitas as covas utilizando a inchada, as plantas foram colocadas num espaçamento aproximado de $30 \mathrm{~cm}$, obedecendo à presença ou ausência do sol, conforme a necessidade da planta, visto que a metade da 
horta ficou com sombra e a outra metade ficou exposta ao sol. Isso pode ser verificado nas FIGURAS 02 e 03.

Após o plantio das mudas (FIGURA 03), os alunos irrigaram a horta. Na FIGURA 03 pode ser observada a horta medicinal após o plantio de todas as mudas.

FIGURA 02: Fotografia do plantio das mudas realizado pelos alunos.

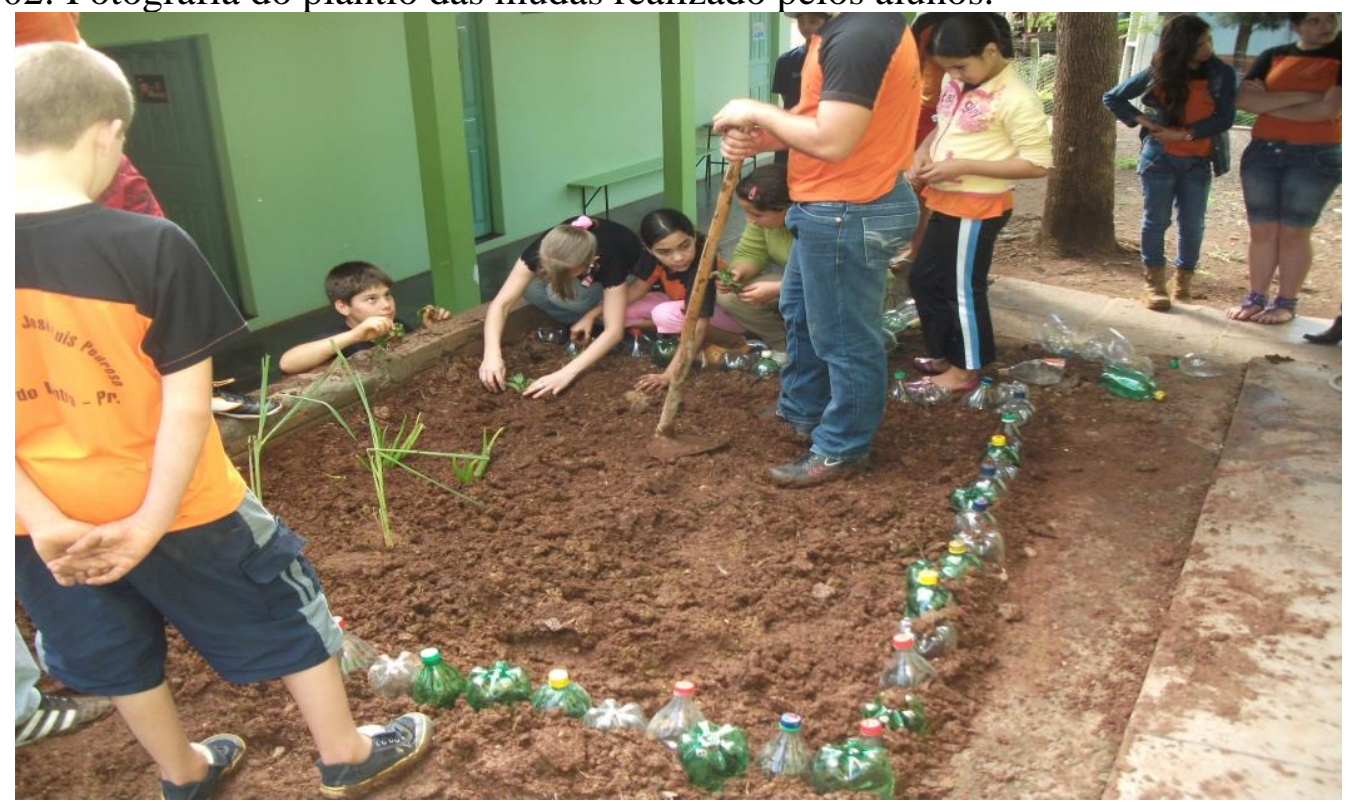

FONTE: Autoras (2012).

FIGURA 03: Fotografia da horta finalizada.

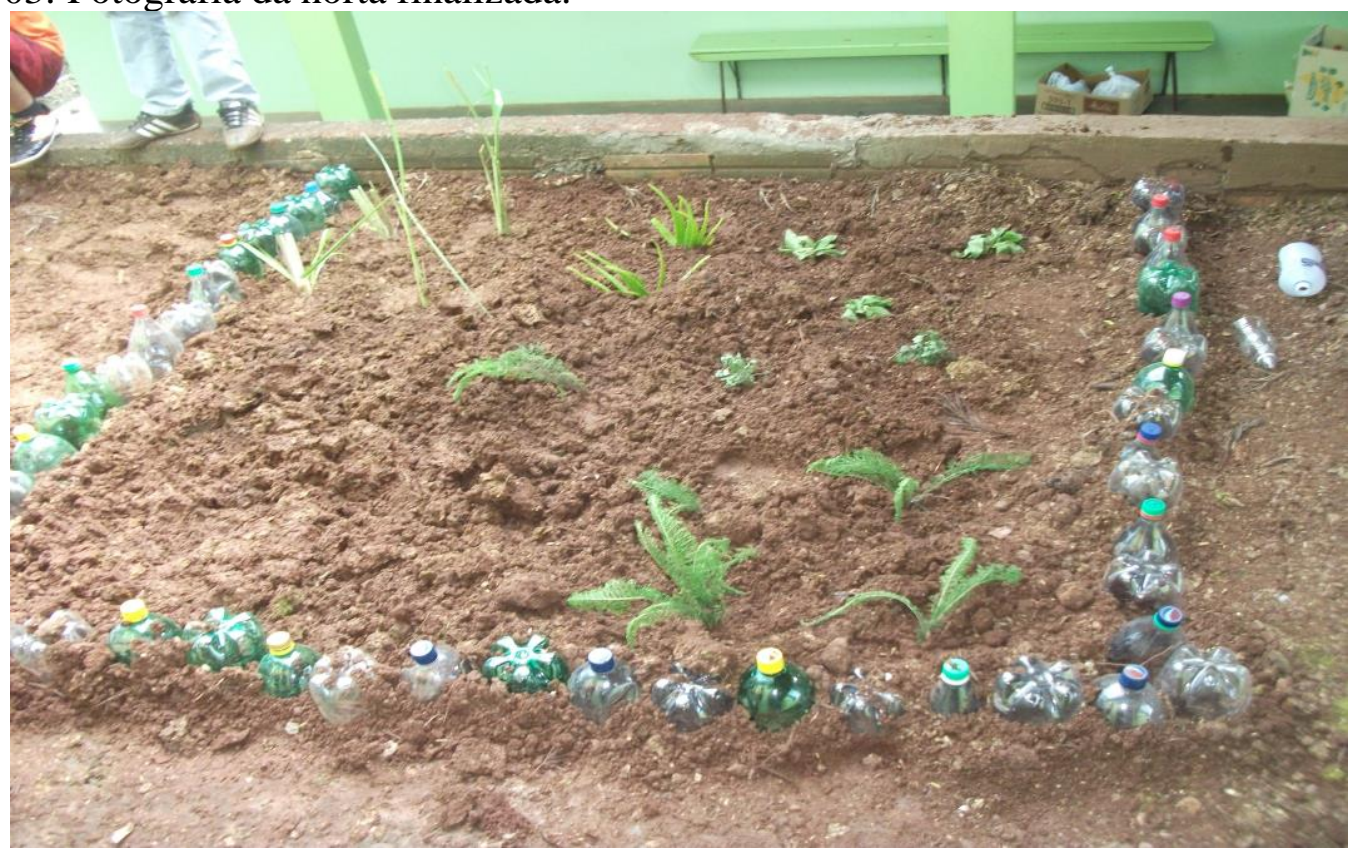

Fonte: Autoras (2012). 
Após o plantio de todas as plantas medicinais, os alunos foram conduzidos até o laboratório de informática para a elaboração de um manual sobre as plantas presentes na horta da escola. Esse manual apresenta: nome comum, indicação e preparo do chá para todas as plantas da horta. Esse momento mostrou-se muito produtivo, pois os alunos foram tirando dúvidas conforme iam pesquisando na internet aspectos relevantes sobre as pantas.

A seguir foi realizada a aplicação de um questionário, contendo perguntas abertas e fechadas, para professores e alunos responderem, os dados foram tabulados e estão apresentados a seguir.

A primeira pergunta foi: "Você tem o costume de tomar chás?", 100\% dos professores afirmaram ter o costume de tomar chás, entre os alunos $58 \%$ responderam que tomam chás (TABELA 01). Nesse aspecto observa-se que os adultos tem maior costume de tomar chás, seja para fins paliativos ou não, do que os adolescentes, isso já era esperado, pois se sabe que os adolescentes não gostam muito de chás.

TABELA 01 - Você tem o costume de tomar chás? Relação das respostas dos alunos e professores quando perguntados se tem o costume de tomar chás.

\begin{tabular}{lcc} 
Você tem o costume de tomar chás? & $\begin{array}{c}\text { Quantidade de } \\
\text { alunos (\%) }\end{array}$ & $\begin{array}{c}\text { Quantidade de } \\
\text { professores (\%) }\end{array}$ \\
\hline Sim & 42 & 100 \\
Não & 58 & 0 \\
Total & 100 & 100 \\
\hline
\end{tabular}

A segunda pergunta feita foi: "Você já fez uso de alguma planta medicinal?", de acordo com a resposta da primeira pergunta, 100\% dos professores, responderam que já haviam feito o uso de plantas medicinais em suas vidas, dentre os alunos, observa-se que uma grande porcentagem (42\%) não lembravam, $53 \%$ já tinham feito uso de plantas e apenas 5\% afirmaram que não haviam feito uso de plantas (TABELA 02).

Conclui-se que uma grande quantidade de alunos não se lembrava de ter usado algum chá, isso remete a importância desse tema ser tratado em sala de aula, pois se sabe o poder paliativo e curativo de algumas plantas e a importância de serem tomadas adequadamente, a fim de proporcionar um melhor conhecimento para os alunos, que possa ser transmitido aos seus pais. 


\section{FAZ CIÊNCIA, VOL. 22, N. 35, JA/JUN DE 2020 - P. 06-08}

Para Pereira e Defani (2013) é essencial o uso correto das plantas com propriedades medicinais, pois traz grandes benefícios para a saúde, ajudando no combate de doenças infecciosas, doenças alérgicas, disfunções metabólicas, entre outras.

Assim, trabalhos como a implementação da horta, podem remeter ao dia a dia do aluno de forma que o educando lembre mais sobre tal tema, principalmente relacionado à saúde, como é o caso do uso de plantas.

TABELA 02 - Você já fez uso de alguma planta medicinal? Relação das respostas dos alunos e professores quando perguntados se já fez uso de alguma planta medicinal.

\begin{tabular}{lcc}
\multicolumn{1}{c}{$\begin{array}{c}\text { Você já fez uso de alguma planta } \\
\text { medicinal? }\end{array}$} & $\begin{array}{c}\text { Quantidade de aluno } \\
(\boldsymbol{\%})\end{array}$ & $\begin{array}{c}\text { Quantidade de } \\
\text { professor }(\boldsymbol{\%})\end{array}$ \\
\hline Sim & 53 & 100 \\
Não & 5 & 0 \\
Não lembro & 42 & 0 \\
Total & 100 & 100 \\
\hline
\end{tabular}

A próxima pergunta foi: "Você acredita na eficácia no tratamento de alguma doença com o uso das plantas?" entre os professores mais uma vez 100\% respondeu acreditar, já entre os alunos 95\% afirmaram acreditar (TABELA 03). Isso mostra que mesmo os alunos não tendo o costume rotineiro de tomar chás, eles acreditam na eficácia dos mesmos no tratamento de doenças, isso é muito importante, pois mostra que o aluno tem interesse pelo assunto e que, principalmente, tomaria o chá das plantas medicinais. Barros (2011) também demonstrou que quase 90\% dos alunos responderam acreditar no uso de plantas no tratamento de doenças.

Segundo Rodrigues e Carvalho (2001), as plantas medicinais atuam no combate às doenças, purificando o organismo, destruindo ou inibindo o desenvolvimento de agentes patogênicos, expelindo toxinas, neutralizando a ação de bactérias, parasitas e outros. Assim, é essencial o trabalho com alunos, para que saibam como utilizar os chás de forma apropriada, principalmente, porque $95 \%$ dos alunos afirmaram acreditar no poder medicinal de tais plantas (TABELA 03). 


\section{FAZ CIÊNCIA, VOL. 22, N. 35, JA/JUN DE 2020 - P. 06-08}

TABELA 03 - Você acredita na eficácia no tratamento de alguma doença com o uso das plantas? Relação das respostas dos alunos e professores quando perguntados se acreditam na eficácia no tratamento de doenças com o uso das plantas.

\begin{tabular}{lcc}
\hline $\begin{array}{c}\text { Você acredita na eficácia no } \\
\text { tratamento de alguma doença } \\
\text { com o uso das plantas? }\end{array}$ & Quantidade de aluno (\%) & $\begin{array}{c}\text { Quantidade de professor } \\
(\%)\end{array}$ \\
\hline Sim & 95 & 100 \\
Não (nunca) & 5 & 0 \\
Total & 100 & 100 \\
\hline
\end{tabular}

A quarta pergunta realizada foi: "Através de quem (ou como) aprendeu a usar plantas medicinais?", dentre os professores 40\% respondeu ter aprendido com os pais e $60 \%$ com os avós, isso mostra que o uso de plantas medicinais vem de um contexto histórico muito longo, onde as pessoas no passado tinham o costume de tomar chás para a cura de todos os tipos de males. Isso vai de acordo com as respostas dos alunos que afirmaram $41 \%$ ter aprendido com os pais, $41 \%$ com os avós (TABELA 04). Corroborando com esses resltados, os estudos de Barros (2011) demonstraram que $73,3 \%$ dos entrevistaram relataram ter aprendido o conhecimento sobre plantas medicinais com os pais e avós. Em contrapartida, Lucena et al., (2013) afirmar que 63\% dos entrevistados aprenderam sobre plantas medicinais com os pais e apenas $20 \%$ com os avós.

Oliveira e Aráujo (2007) lembram que as plantas medicinais são uma das mais remotas “armas" utilizadas pelos seres humanos no tratamento de doenças. A utilização de plantas na prevenção e/ou na cura de doenças é um hábito que sempre existiu na história da humanidade (OLIVEIRA; ARAÚJO, 2007). Isso justifica porque muitas pessoas aprendem a utilizar plantas medicinais com avós e pais.

Apareceu entre os alunos, 18\% ter aprendido com a professora (TABELA 04), isso é importante, pois mostra que alguns educandos aprenderam mais sobre plantas na escola com o professor, remetendo o papel da escola em aplicar conhecimentos práticos que fujam apenas do conhecimento teórico. A escola tem papel fundamental oferecendo grandes possibilidades de pesquisa que podem beneficiar principalmente a comunidade escolar, porque fala dela, de seus anseios, de problemas vivenciados no dia a dia, enfim, coloca-a em foco (BERNARDES, 2012). 


\section{FAZ CIÊNCIA, VOL. 22, N. 35, JA/JUN DE 2020 - P. 06-08}

TABELA 04 - Através de quem (ou como) aprendeu a usar plantas medicinais? Relação das respostas dos alunos e professores quando perguntados com quem aprendeu a usar plantas medicinais (nessa pergunta poderia ser assinalada mais de uma alternativa).

\begin{tabular}{lcc}
\hline $\begin{array}{c}\text { Através de quem (ou como) } \\
\text { aprendeu a usar plantas } \\
\text { medicinais? }\end{array}$ & $\begin{array}{c}\text { Quantidade de aluno (\%) } \\
\text { Pais }\end{array}$ & $\begin{array}{c}\text { Quantidade de professor } \\
(\%)\end{array}$ \\
Avós & 41 & 40 \\
Vizinhos & 41 & 60 \\
Televisão & 0 & 0 \\
Profissionais de saúde & 0 & 0 \\
Livros & 0 & 0 \\
Professor & 0 & 0 \\
Total & 18 & 0 \\
\hline
\end{tabular}

Também foi perguntado aos alunos e professores se faziam uso correto das plantas medicinais, nessa questão os entrevistados poderiam colocar porque acham que utilizam as plantas corretamente ou não. Entre os professores $100 \%$ afirmaram que fazem uso correto das plantas, já entre os alunos, 63\% afirmou que sim e 37\% que não (TABELA 05). Portanto, a palestra teve grande importância, pois os alunos conseguiram observar que de alguma forma faziam uso inadequado das plantas, como um aluno colocou: “[...] eu não sabia que o melhor é não colocar açúcar nos chás feitos com plantas medicinais, principalmente para quem tem diabetes”. Outro aluno ainda acrescentou: “[...] antes eu fazia de qualquer jeito e agora eu sei a medida certa”.

Para Pêgo (2012) o uso inadequado de chás pode comprometer a saúde dos usuários. Em muitas situações, as pessoas sentem algo e recorrem aos chás, simplesmente, pela indicação de alguém, mas na verdade, cada chá possui uma propriedade específica e um benefício, então é necessário saber se realmente o chá serve para aquilo que a pessoa está sentido. 


\section{FAZ CIÊNCIA, VOL. 22, N. 35, JA/JUN DE 2020 - P. 06-08}

TABELA 05 - Você acha que faz uso correto das plantas medicinais? Relação das respostas dos alunos e professores quando perguntados se fazem uso correto das plantas medicinais.

\begin{tabular}{lcc}
$\begin{array}{c}\text { Você acha que faz uso correto } \\
\text { das plantas medicinais? }\end{array}$ & Quantidade de aluno (\%) & $\begin{array}{c}\text { Quantidade de professor } \\
(\%)\end{array}$ \\
\hline Sim & 63 & 100 \\
Não & 37 & 0 \\
Total & 100 & 100 \\
\hline
\end{tabular}

A sexta pergunta realizado foi: "Você acha que aulas práticas, como o da horta medicinal, trazem um melhor aprendizado?". Todos os entrevistados, professores e alunos, responderam que sim (TABELA 06). Nesse contexto destaca-se o aprendizado e o interesse dos alunos e professores na promoção de aulas diferentes, onde os alunos passam a desenvolver o papel de cidadãos ativos na comunidade escolar, juntamente com o envolvimento dos professores.

Para Antunes (2001) a aula transforma-se num momento privilegiado de troca de ideias, de prática autocrítica, de interajuda, de enriquecimento mútuo e de crescimento, levando os alunos a recombinar a sua teia de crenças, a alargar os seus horizontes e a criar novas significações (ANTUNES, 2001). Assim, torna-se uma comunidade de educação, investigação e aprendizagem.

Os resultados de Barreira (2001) mostraram que, aproximadamente, 75\% dos alunos entrevistados gostam de aulas participativas. Isso demonstra que os alunos gostam e preferem aulas nas quais podem participar, isso é demonstrado pelo resultado de $100 \%$ dos educandos (TABELA 06) acreditarem que essa prática, de implementação da horta medicinal, melhora o aprendizado.

TABELA 6 - Você acha que aulas práticas, como o da horta medicinal, trazem um melhor aprendizado? Relação das respostas dos alunos e professores quando perguntados se aulas práticas, como o da horta medicinal, trazem um melhor aprendizado.

\begin{tabular}{lcc}
\hline $\begin{array}{c}\text { Você acha que aulas práticas, } \\
\text { como o da horta medicinal, } \\
\text { trazem um melhor } \\
\text { aprendizado? }\end{array}$ & Quantidade de aluno (\%) & $\begin{array}{c}\text { Quantidade de professor } \\
(\%)\end{array}$ \\
\hline Sim & 100 & 100 \\
Não & 0 & 0 \\
Total & 100 & 100 \\
\hline
\end{tabular}




\section{FAZ CIÊNCIA, VOL. 22, N. 35, JA/JUN DE 2020 - P. 06-08}

A sétima pergunta: “A implementação da horta medicinal na escola do campo é importante para a escola?" mostrou que 100\% dos entrevistados, entre professores e alunos, acreditam ser importante essa prática para a escola do campo (TABELA 07). Nesse pergunta os entrevistados poderiam colocar porque acham essa prática importante. Dentre os professores entrevistados, algumas das respostas foram: "É um resgate dos ensinamentos [...]", "Auxilia no uso na hora que precisar e não tem remédio em casa", "Para que os alunos levem as suas famílias formas econômicas de tratamento a vários problemas de saúde", "É uma boa maneira de incluir no currículo na escola do campo envolvendo assim os conceitos do campo".

Com relação às respostas dadas pelos alunos, destacam-se algumas: "Porque quando não tinha agente ficava com dor de cabeça e não tinha nada para tomar de chá e agora tem”, destacando a sua importância, principalmente, porque não se podem dar remédios aos alunos, outra resposta foi “[...] podemos ter um melhor aprendizado, conhecer muitas plantas que eu não conhecia e pra que elas servem e como devem ser preparadas", isso mostra a necessidade de um aprendizado adequado do preparo e indicação das diversas plantas. Outra resposra importante dado por um aluno foi "Podemos aprender sobre as plantas que estudamos no livro didático", remetendo a necessidade do trabalho prático voltado ao conteúdo teórico.

Observa-se nesse contexto, que a horta medicinal além de mostrar conhecimento importante para utilização correta de plantas medicinais, envolvem conceitos da escola do campo, que são de extrema necessidade para alunos que ali irão se formar.

Segundo Noal (2012) ao pensar em escolas do campo, em práticas pedagógicas e tecnologias, é essencial partir do espaço coletivo existente, com sua intrincada rede de costumes, crenças, valores, rituais e contradições que permeiam os saberes do campo e que se comprovam no dia a dia da vida campesina. Destacando a utilização de plantas medicinais, que é costumeiro para povos do campo, os quais muitas vezes não possuem instruções e acabam erroneamente utilizando esses chás, dessa forma, o ensinamento passado aos alunos, é muito importante, pois tira dúvidas e leva para cada família como deve-se utilizar e para que são recomendados os chás. 


\section{FAZ CIÊNCIA, VOL. 22, N. 35, JA/JUN DE 2020 - P. 06-08}

TABELA 7 - A implementação da horta medicinal na escola do campo é importante para a escola? Relação das respostas dos alunos e professores quando perguntados se a implementação da horta medicinal na escola do campo é importante.

\begin{tabular}{lcc}
\hline $\begin{array}{c}\text { A implementação da horta } \\
\text { medicinal na escola do campo } \\
\text { é importante para a escola? }\end{array}$ & Quantidade de aluno (\%) & $\begin{array}{c}\text { Quantidade de professor } \\
(\%)\end{array}$ \\
\hline Sim & 100 & 100 \\
Não & 0 & 0 \\
Total & 100 & 100 \\
\hline
\end{tabular}

A última pergunta realizada foi: "O que achou da implementação da horta medicinal na sua escola?", portanto, essa pergunta era descritiva.

Entre os professores, destacam-se como respostas: "Foi excelente, ótima ideia que faz nós professores mudarem os conteúdos voltados para o campo", "É uma forma de atingir as famílias diretamente através de seus filhos (alunos), levando o conhecimento que por sua vez é gratuito e natural com grande eficácia no tratamento de muitas situações", "Muito bom, a professora é ótima e muito inteligente, ensinou muito bem e tirou dúvidas existentes em todos nós”.

Entre os alunos, destacam-se algumas das respostas: “[...] A gente pode levar esse conhecimento para casa", "Achei ótimo porque eu nunca tinha plantado plantas medicinais [...] aqui eu meti a mão na massa, foi muito legal, adorei”, “[...] aprendi coisas que eu não sabia”, "Achei legal, gostei e acho que poderíamos fazer isto de novo", pode-se observar que os alunos sempre ficam atraídos por aulas diferentes que tragam a tona assuntos do dia a dia do aluno, como é o caso da horta, além de poder levar esse conhecimento para casa e aplica-lo.

Outras respostas foram: "Eu achei ótimo porque assim quando alguém ficar doente temos o que tomar e podemos aprender a fazer uma horta com garrafas pet para não deixa-las no meio ambiente. Assim podemos fazer uma em casa e muitas vezes não vai precisar comprar remédios". Portanto, a implementação da horta medicinal envolve vários aspectos, como saúde, campo, meio ambiente, entre outros, os quais, os alunos gostam de trabalhar.

Nesse contexto, afirma-se que a implementação da horta foi muito produtiva, pois quando avaliado pelos alunos e professores, foram apontadas vários pontos positivos com relação a essa prática. Desta forma, destaca-se a necessidade e a importância que trabalhos como esses sejam 


\section{FAZ CIÊNCIA, VOL. 22, N. 35, JA/JUN DE 2020 - P. 06-08}

elaborados em escolas de outras localidades, com o intuito de envolver os alunos e os professores em atividades práticas, relacionadas com conteúdos curriculares e saberes empíricos.

\section{Considerações Finais}

A implementação de hortas de plantas medicinais, como alternativas de aulas diferenciadas, mostra-se de grande valia, principalmente quando se trabalha em escolas do campo, pois traz para dentro da escola o dia a dia do aluno, sobretudo, porque a grande maioria da população do campo possuem hortas em suas propriedades e/ou fazem uso das mesmas.

Outro aspecto importante é a relação dos conteúdos de Ciências e Biologia que dá para realizar durante a implementação, como é o caso da utilização de garrafas pet como benefício para o meio ambiente, pois se sabe que plásticos são responsáveis por grande parte da poluição ambiental. Pode-se ainda, fazer relações com conteúdos do reino plantae, solo, água, saúde, entre outros.

Destaca-se, ainda, que o espaço anteriormente ocupado hoje pela horta, estava sem utilização, e agora além das plantas medicinais ali cultivadas, a escola pode utilizar o restante do espaço para o plantio de verduras e hortaliças.

Portanto, a utilização de práticas diferenciadas se mostra muito importante, especialmente, pela escola do campo, a qual deve realizar, sempre que possível, aulas voltadas ao contexto ao qual os alunos estão inseridos.

\section{Referências}

ANTUNES, M. Teoria e prática pedagógica, Lisboa, Instituto Piaget, 2001.

ARMSTRONG, D. A survey of community gardens in upstate New York: Implications for health promotion and community development. Health Place, v. 6, n. 4, p. 319-27, dez. 2000.

ARNOUS, A. H.; SANTOS, A. S.; BEINNER R. P. C. Plantas medicinais de uso caseiro Conhecimento popular e interesse por cultivo comunitário. Revista Espaço para a Saúde, Londrina, v. 6, n. 2, p. 1-6, jun. 2005.

BARREIRA, A. O ensino da História no $3^{\circ}$ ciclo de escolaridade obrigatória - os interesses dos alunos e a prática docente. Revista da Faculdade de Letras, III série, Porto, v. 2, p. 41-50, 2001.

BARROS, A. T. Implantação de uma horta medicinal como estratégia de educação ambiental em uma escola pública de Patos - PB, Brasil. Revista de Biologia e Farmácia, Paraíba, v. 5, n. 2, p. 7382, jun. 2011.

BERNARDES, A. O. Pesquisa na escola: Utilização de plantas medicinais pela comunidade escolar. Disponível em: <http://www.educacaopublica.rj.gov.br/suavoz/0149.html>. Acesso em: 16 de julho de 2013. 
KRASILCHIK, M. Prática de Ensino de Biologia. São Paulo: Editora Universidade de São Paulo, 2004.

LUCENA, D. da S.; SOUZA, P. F. de; MARINHO, M. das G. V.; FERREIRA, C. D.; LOPES, I. S.; MEDEIROS, J. X. de. Plantas medicinais utilizadas na comunidade urbana de Lagoa, sertão Paraibano. Rev. Biol. Farm., Paraíba, v. 9, n. 1, p. 105-115, jun. 2013.

MORGADO F. S.; SANTOS, M. A. A. dos. A horta escolar na educação ambiental e alimentar: experiência do Projeto Horta Viva nas escolas municipais de Florianópolis, Florianópolis: Universidade Federal de Santa Catarina, 2006. 50 p. (Graduação em Agronomia). Disponível em: < https://periodicos.ufsc.br/index.php/extensio/article/view/9531>. Acesso em: 17/08/2012.

NOAL, M. L. Educação do campo: escolas, práticas pedagógicas, tecnologias. Universidade Federal do Mato Grosso do Sul. Disponível em: <http://www.encontroobservatorio.unb.br/arquivos/artigos/120>. Acesso em: 17/08/2012.

OLIVEIRA C. J, ARAÚJO, T. L. Plantas medicinais: usos e crenças de idosos portadores de hipertensão arterial. Revista Eletrônica de Enfermagem, v. 9, n. 1, p. 93-105, mar. 2007.

ORGANIZAÇÃO CANTO VERDE. Plantas medicinais - Manejo. 2009. Disponível em: <http://www.cantoverde.org/plantasmed03.htm\#ixzz20vd9HbKn>. Acesso em: 18/07/2012.

PÊGO, A. Pesquisa avalia o uso correto das plantas medicinais. Fundação de Amparo à Pesquisa do Estado do Amazonas. Disponível em: <http://www.fapeam.am.gov.br/noticia.php?not=6103> . Acesso em: 04/09/2012.

PEREIRA, M. C.; DEFANI, M. A. Plantas medicinais: Modificando conceitos. Disponível em: < http://www.diaadiaeducacao.pr.gov.br/portals/pde/arquivos/284-4.pdf>. Acesso em: 16/07/2013.

RODRIGUES, V. E. G.; CARVALHO, D. A. Levantamento etnobotânico de plantas medicinais no domínio do cerrado na região do Alto Rio Grande. Minas Gerais. Ciênc. Agrotec., v. 25, p. 102-123, jan. 2001.

UNIVERSIDADE DE SÃO PAULO. Plantas medicinais e aromáticas. Cultivo de horta medicinal. Disponível em: <http://www.esalq.usp.br/siesalq/pm/p05.pdf>. Acesso em: 20/06/2012.

UNTALER, L. de O.; FERNANDES, C. R. M. G.; OLIVEIRA, L. de. Plantas medicinais: da horta para escola. 2011. Disponível em: <http://portaldoprofessor.mec.gov.br/fichaTecnicaAula. html?aula=27532>. Acesso em: 25/06/2012.

\section{Recebido em 29/04/202 - Aprovado em 15/06/2020.}

